\title{
Perbandingan tingkat kebocoran mikro resin komposit bulk-fill dengan teknik penumpatan oblique incremental dan bulk
}

\author{
Dimas Puja Permana*, Billy Sujatmiko**, Rinda Yulianti*** \\ *Program Studi Kedokteran Gigi, Fakultas Kedokteran, Universitas Sriwijaya, Palembang, Sumatera Selatan, Indonesia \\ **Bagian Konservasi Gigi, Program Studi Kedokteran Gigi, Universitas Sriwijaya, Palembang, Sumatera Selatan, Indonesia \\ ***Bagian Konservasi Gigi, Rumah Sakit Khusus Gigi dan Mulut, Palembang, Sumatera Selatan, Indonesia \\ *JI Raya Palembang - Prabumulih Km. 32 Indralaya, Palembang, Sumatera Selatan, Indonesia; \\ e-mail: dimas_antariksa70@yahoo.com
}

Submisi: 15 Juni 2015; Penerimaan: 23 Juli 2016

\begin{abstract}
ABSTRAK
Resin komposit bulk-fill adalah resin komposit yang dirancang untuk mempercepat proses aplikasi resin komposit. Konsep bulk-fill memungkinkan resin komposit ditumpat sekaligus $4 \mathrm{~mm}$ dan mengalami pengerutan polimerisasi minimal. Penelitian ini bertujuan mengetahui efek teknik penumpatan (oblique incremental/bulk) pada tingkat kebocoran mikro resin komposit bulk-fill. Sampel berjumlah 32 gigi premolar rahang atas disimpan di dalam aquades, dipreparasi kavitas kelas I berbentuk persegi, kedalaman kavitas 4 mm (3 x $3 \times 4)$. Sampel dibagi dalam dua kelompok, kelompok 1 restorasi teknik oblique incremental dan kelompok 2 teknik bulk. Sampel kemudian disimpan di dalam inkubator pada suhu $37^{\circ} \mathrm{C}$ selama 24 jam, kemudian dilakukan prosedur thermocycling manual 100 putaran pada suhu $5^{\circ} \mathrm{C}$ dan 55 ${ }^{\circ} \mathrm{C}$. Kebocoran mikro diukur menggunakan digital microscope pembesaran $100 \mathrm{x}$ dalam satuan milimeter menggunakan penggaris mikrometer mikroskop dengan ketelitian $0,1 \mathrm{~mm}$ setelah sampel direndam dalam larutan methylene blue 0,3\% selama 24 jam dan dipotong pada pertengahan restorasi menggunakan separating disc. Hasil pengukuran tingkat kebocoran mikro menunjukkan pada kelompok 1 nilai kebocoran mikro yang terjadi berkisar 1,0 mm - 2,7 mm dengan rata-rata 1,625 mm, pada kelompok 2 kebocoran mikro yang terjadi berkisar 3,6 mm - 4,0 mm dengan rata-rata 3,763 $\mathrm{mm}$. Data di analisis menggunakan uji T-test. Hasil analisis menunjukkan terdapat perbedaan yang signifikan antara kedua kelompok $(p<0,05)$. Kesimpulan penelitian ini adalah restorasi resin komposit bulk-fill pada kavitas kelas I dengan teknik oblique incremental menghasilkan tingkat kebocoran mikro yang lebih kecil dibandingkan dengan teknik bulk.
\end{abstract}

Kata kunci: bulk, bulk-fill, kebocoran mikro, oblique incremental

\begin{abstract}
Micoleakage comparison of bulk-fill composite beetwen oblique incremental and bulk placement techniques. Resin composite bulk-fill was a new type of resin composite that speed up application process of composite. The concept of bulk-fill composite allows composite to fill at a depth of $4 \mathrm{~mm}$ and minimizes polymerization shrinkage. This study aims to determine the comparison of placement techniques (oblique incremental/bulk) of bulk-fill composite on microleakage in class I preparations. Thirty two human maxillary premolar were stored in distilled water, then Class I preparations were made with the depth of the cavity which was $4 \mathrm{~mm}(3 \times 3 \times 4)$. The teeth were randomly divided into two groups, group 1 uses oblique incremental placement technique and group 2 with bulk placement technique. Samples were stored in an incubator at a temperature of $37^{\circ} \mathrm{C}$ for 24 hours, then it was thermocycled manually, 100 cycles at temperature between $5^{\circ} \mathrm{C}$ and $55^{\circ} \mathrm{C}$. Microleakage was measured using a digital microscope with a $100 \mathrm{X}$ magnification in millimeters using a microscope micrometer calibration ruler with 0,1 $\mathrm{mm}$ level of accuracy after immersion in 0,3\% methylene blue and sectioned using separating disc. The result of this study revealed that in group 1 microleakage range was $1.0 \mathrm{~mm}-2.7 \mathrm{~mm}$ with an average $1.625 \mathrm{~mm}$, and in group 2 microleakage range was $3.6 \mathrm{~mm}-4.0 \mathrm{~mm}$ with an average of $3.763 \mathrm{~mm}$. The data were analyzed using T-test. The analysis showed a significant difference between two groups ( $p$ <.05). The conclusion of this study was bulk-fill composite in class I cavities with oblique incremental placement technique produces less microleakage than bulk placement technique.
\end{abstract}

Keywords: bulk, bulk-fill, microleakage, oblique incremental

\section{PENDAHULUAN}

Resin komposit merupakan bahan restorasi yang paling banyak digunakan dalam bidang kedokteran gigi saat ini. Resin komposit terdiri atas tiga komponen utama, yaitu matriks, filler, dan coupling agent, serta memiliki keunggulan yaitu warna yang menyerupai warna gigi asli, memiliki nilai estetis yang baik dan biokompatibilitas yang tinggi. Kekurangan dari resin komposit yaitu adanya pengerutan pada saat polimerisasi (polymerization shrinkage). ${ }^{1}$ 
Pengerutan polimerisasi disebabkan komponen matriks pada resin komposit. ${ }^{2}$ Matriks resin komposit umumnya mengandung Bis-GMA. Resin komposit dengan kandungan matriks tersebut digolongkan sebagai resin komposit konvensional. Matriks resin komposit tersusun atas monomermonomer yang memiliki ikatan karbon rantai ganda dan terdapat jarak antar monomer. Saat terjadi polimerisasi monomer akan berikatan satu sama lain untuk membentuk polimer dengan jalan pemutusan ikatan karbon menjadi rantai tunggal. Pembentukan polimer akan menghilangkan jarak antar monomer yang menyebabkan volume dari resin komposit berkurang. Pengerutan pada saat polimerisasi menyebabkan terbentuknya kebocoran mikro yaitu celah antara permukaan gigi dan resin komposit. Kebocoran mikro dapat menyebabkan terjadinya karies sekunder, sensitivitas pasca penumpatan, dan kegagalan restorasi. ${ }^{3,4,5}$

Saat ini telah dikembangkan resin komposit dengan komponen matriks baru yaitu resin komposit bulk-fill. Komponen matriks pada resin komposit bulkfill memiliki ikatan molekul yang lebih panjang dan jarak antar monomer yang lebih pendek sehingga volume resin komposit yang berkurang pada saat polimerisasi lebih kecil.6.7 Resin komposit bulkfill dapat ditumpat dan disinar sampai kedalaman $4 \mathrm{~mm}$ sehingga mempercepat waktu restorasi. Berdasarkan penelitian Sagob, ${ }^{8}$ resin komposit bulk-fill menghasilkan kebocoran mikro yang lebih kecil dibandingkan resin komposit konvensional. Usaha untuk mengurangi kebocoran mikro resin komposit konvensional yaitu dengan mengurangi nilai $c$-factor melalui modifikasi teknik penumpatan. Teknik penumpatan yang dapat mengurangi nilai c-factor adalah teknik incremental yang merupakan teknik penumpatan resin komposit secara bertahap. ${ }^{4}$ Berdasarkan penelitian Roppa dkk., ${ }^{9}$ teknik incremental menghasilkan kebocoran mikro yang lebih kecil dibandingkan penumpatan secara sekaligus (bulk) pada resin komposit konvensional. Resin komposit bulk-fill tetap mengalami kebocoran mikro, hal ini mendorong dilakukan penelitian untuk menghasilkan kebocoran mikro yang lebih minimal lagi. Furness dkk., ${ }^{10}$ melakukan penumpatan secara horizontal incremental dan mengukur tingkat kebocoran mikro dibandingkan penumpatan secara sekaligus (bulk), namun hasilnya menunjukkan tidak ada perbedaan yang signifikan.

Selain teknik horizontal incremental, terdapat teknik oblique incremental. Berdasarkan penelitian Moezyzadeh, ${ }^{11}$ pada resin komposit konvensional teknik oblique incremental menghasilkan kebocoran mikro yang lebih kecil dibandingkan teknik horizontal incremental, sedangkan penelitian untuk membandingkan kebocoran mikro antara teknik oblique incremental dan bulk belum pernah dilakukan. Berdasarkan hal tersebut, penelitian ini bertujuan untuk membandingkan tingkat kebocoran mikro resin komposit bulk-fill dengan teknik penumpatan oblique incremental dan bulk.

\section{METODE PENELITIAN}

Sampel berjumlah 32 gigi premolar rahang atas yang telah diekstraksi, dipilih yang tidak karies, bebas tambalan dan foramen apikal telah tertutup sempurna. Gigi dibersihkan dan telah disimpan dalam aquadest serta dibekukan maksimal 90 hari pasca pencabutan, sampai gigi digunakan. ${ }^{12}$ Setelah dibersihkan dan disimpan, kemudian akar gigi ditanam ke dalam balok gips sebatas servikal untuk mempermudah preparasi.

Gigi dipreparasi kavitas kelas I, dibuat outline pada permukaan oklusal gigi dengan terlebih dahulu ditentukan titik tengah dari oklusal gigi, kemudian diukur dari titik tengah ke arah mesial 1,5 $\mathrm{mm}$, ke arah distal $1,5 \mathrm{~mm}$, ke arah bukal $1,5 \mathrm{~mm}$, dan ke arah palatal $1,5 \mathrm{~mm}$ sehingga didapatkan diameter kavitas $3 \mathrm{~mm}$ (gambar 1.), gigi dipreparasi dengan kedalaman kavitas $4 \mathrm{~mm}$ menggunakan bur diamond (round, silindris, inverted cone ${ }^{13}$

Pengelompokan sampel penelitian. Gigi dipilih secara random untuk tiap kelompok 1 dan 2. Masingmasing terdiri dari 16 buah gigi. Kelompok 1 yang akan ditumpat resin komposit bulkfill dengan teknik penumpatan oblique incremental dan kelompok 2 yang akan ditumpat dengan teknik bulk.

Aplikasi bahan bonding (scotch bond universal) ke kavitas menggunakan microbrush selama 20 detik, keringkan menggunakan air spray selama 5 detik untuk menguapkan zat pelarut, terakhir di sinar selama 10 detik. Gigi ditumpat menggunakan resin komposit bulk-fill. 




Gambar 1. Metode penentuan desain kavitas



Gambar 2. Penumpatan secara oblique incrementals: penumpatan resin komposit secara bertahap yang dilakukan sebanyak 4 lapis

Kelompok 1 ditumpat secara oblique incremental yang merupakan penumpatan resin komposit secara bertahap yang dilakukan sebanyak 4 lapis. Lapisan pertama setebal $1 \mathrm{~mm}$ diukur dengan menggunakan sonde lurus yang diberi rubber stop pada ujungnya dan dibuat skala dengan tingkat ketelitian $1 \mathrm{~mm}$ menggunakan spidol hitam. Kedalaman $1 \mathrm{~mm}$ dipastikan dengan melihat skala pada sonde yang dihitung dari pangkal kavitas ke lapisan pertama sedalam $3 \mathrm{~mm}$. Lapisan kedua dan ketiga setebal $2 \mathrm{~mm}$ diaplikasikan secara diagonal, untuk memastikan kedalaman $2 \mathrm{~mm}$ digunakan cara sebelumnya menggunakan sonde lurus sedalam $1 \mathrm{~mm}$, dan lapisan terakhir setebal $1 \mathrm{~mm}$ diaplikasikan untuk menyelesaikan tumpatan (Gambar 2) dan kelompok 2 ditumpat secara bulk yang merupakan penumpatan resin komposit secara sekaligus ke dalam kavitas sedalam $4 \mathrm{~mm}$ (Gambar 3) menggunakan plastis instrument lalu di sinar selama 20 detik. Intensitas penyinaran 1000 $\mathrm{mW} / \mathrm{cm}^{2}$.

Semua sampel penelitian direndam di dalam $20 \mathrm{cc}$ aquadest menggunakan tabung mika dan disimpan di inkubator dengan suhu $37^{\circ} \mathrm{C}$ selama 24 jam. Proses thermocycling sampel dilakukan secara manual sebanyak 100 kali pada suhu antara $5{ }^{\circ} \mathrm{C}$ dan $55^{\circ} \mathrm{C} .{ }^{14}$ Waktu perendaman dalam setiap suhu 20 detik dan waktu perpindahan antar suhu 10 detik. ${ }^{15}$

Sampel direndam dalam larutan methylene blue $0,3 \%$. Ujung akar gigi ditutup terlebih dahulu dengan menggunakan sticky wax untuk menghindari zat warna berpenetrasi melalui area ujung akar. Seluruh permukaan gigi dilapisi dengan cat kuku kecuali pada area restorasi terutama pinggiran restorasi. Sampel direndam dalam larutan methylene blue 0,3\% selama 24 jam di dalam tabung mika, setelah itu sampel dibersihkan menggunakan pelarut cat kuku (aseton), diirigasi menggunakan aquades dan dikeringkan.

Pengukuran Kebocoran Mikro dilakukan dengan cara sampel dipotong menggunakan separating disc pada pertengahan restorasi sejajar sumbu panjang gigi dan tegak lurus bidang oklusal. Setelah itu sampel di pendam di dalam baseplate wax berbentuk setengah lingkaran dengan diameter $1 \mathrm{~cm}$.

Pada masing-masing kelompok, kedalaman penetrasi methylene blue dievaluasi sepanjang dinding restorasi pada kedua sisi (mesial dan distal) dan dipilih salah satu sisi dengan penetrasi methylene blue terdalam. Cara pengukuran kedalaman penetrasi methylene blue dilakukan dengan menggunakan USB Digital Microscope pada pembesaran 100x. Ukuran penetrasi methylene blue didapatkan dengan melihat ukuran yang ditunjukkan pada mini skala. Hasil akhir yang didapatkan dianalisis menggunakan uji independent sample t-test. Perbedaan yang signifikan apabila tercapai $\mathrm{P} \leq 0,05$. 


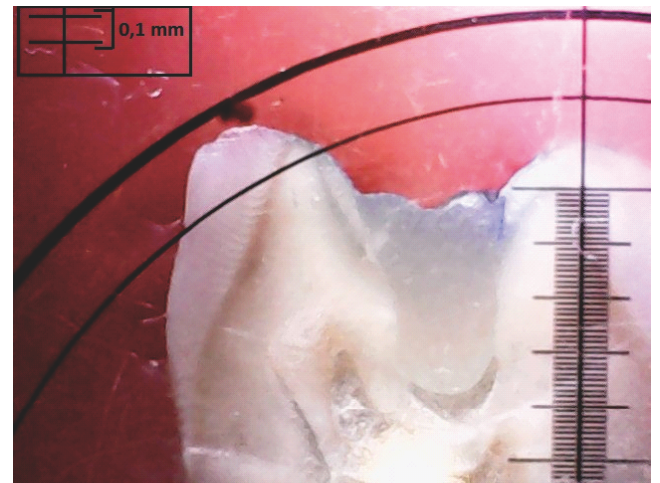

(A)

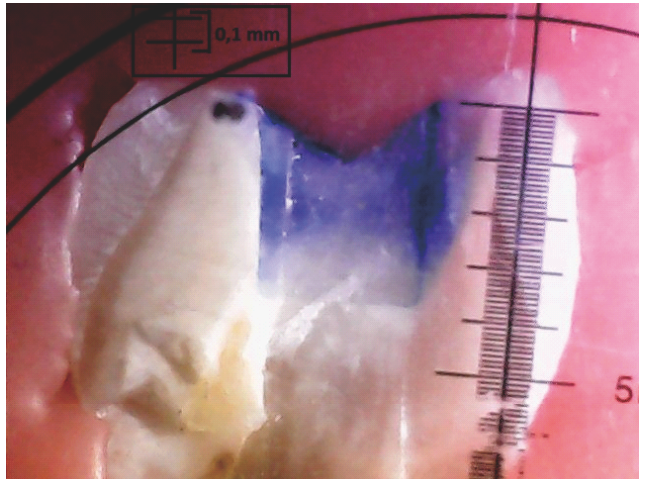

(B)

Gambar 4. Resin komposit bulk-fill (A) dengan penumpatan oblique incremental (B) dengan penumpatan bulk

\section{HASIL PENELITIAN}

Hasil pengukuran tingkat kebocoran mikro pada restorasi resin komposit bulk-fill dapat dilihat pada Gambar 4. Hasil pengamatan kebocoran mikro pada restorasi kavitas kelas I menunjukkan pada kelompok 1 yang dilakukan restorasi dengan teknik oblique incremental nilai kebocoran mikro rata-rata 1,625 mm, dan pada kelompok 2 yang dilakukan restorasi dengan teknik bulk nilai kebocoran mikro rata-rata 3,763 $\mathrm{mm}$ (Tabel 1).

Berdasarkan Tabel 1 didapatkan nilai $p<0,05$. Hal ini menunjukkan bahwa terdapat perbedaan yang signifikan pada tingkat kebocoran mikro resin komposit bulk-fill antara teknik penumpatan oblique incremental dan bulk.

Tabel 1. Nilai perbandingan antar kelompok

\begin{tabular}{llll}
\hline Kelompok & Oblique Incremental & Bulk & p. \\
\hline Nilai & Mean \pm SD & Mean \pm SD &, 000 \\
& $1,625 \pm 0,45$ & $3,763 \pm 0,136$ & \\
\hline
\end{tabular}

\section{PEMBAHASAN}

Teknik penumpatan oblique incremental pada resin komposit bulk-fill menghasilkan kebocoran mikro yang lebih kecil dibandingkan teknik bulk. Kebocoran mikro pada resin komposit bulkfill dipengaruhi oleh polymerization shrinkage yang menyebabkan terbentuknya polymerization shrinkage stress pada resin komposit. Polymerization shrinkage adalah pengerutan yang terjadi selama proses polimerisasi. ${ }^{1}$ Polimerisasi merupakan reaksi kimia yang terjadi saat molekul resin yang disebut monomers berikatan satu dengan yang lain membentuk molekul dengan ikatan rantai yang lebih panjang yang disebut polimer. ${ }^{16}$

Polimerisasi komposit terbagi kedalam dua fase, yaitu pre dan post gel. Pada fase pregel, resin komposit berbentuk pasta sehingga monomer mampu bergerak (flow) saling mendekat membentuk polimer. Pada fase tersebut terjadi polymerization shrinkage, tetapi daya flow resin mampu mengimbangi polymerization shrinkage sehingga tidak terbentuk polymerization shrinkage stress pada resin komposit. ${ }^{16}$ Pada fase post-gel, resin berubah bentuk dari pasta menjadi solid. Pada fase ini resin komposit menjadi kaku (rigid) sehingga tidak dapat mengimbangi polymerization shrinkage yang terus berlanjut, hal ini menyebabkan terbentuknya polymerization shrinkage stress di dalam resin komposit. ${ }^{17,18,19}$ Stress yang terbentuk menyebabkan kegagalan perlekatan sehingga terbentuk kebocoran mikro.

Besarnya polymerization shrinkage stress yang terbentuk pada tumpatan resin komposit dipengaruhi oleh beberapa faktor, yaitu rasio permukaan bebas dan yang berikatan (c-factor) dan ketebalan bahan. ${ }^{20,21,22,23}$ Pada permukaan resin komposit yang tidak berikatan dengan struktur gigi, pergerakan monomer (flow) akan bebas sehingga menghasilkan mekanisme relaksasi terhadap stress yang terbentuk, sedangkan pada permukaan yang berikatan dengan struktur gigi pergerakan monomer akan terbatas dan tertahan, hal ini menyebabkan stress yang terbentuk lebih besar. ${ }^{18}$ Choi $d k k .{ }^{20}$ dalam penelitiannya menyatakan tingkat kebocoran 
mikro akan berkurang dengan menurunnya nilai dari $c$-factor dikarenakan stress yang terbentuk kecil. Penumpatan resin komposit bulk-fill dengan teknik oblique incremental menurunkan nilai c-factor sehingga kebocoran mikro yang terjadi lebih kecil dibandingkan teknik bulk.

Giachetti dkk., ${ }^{21}$ dalam penelitiannya menyatakan pada penumpatan resin komposit dengan ketebalan bahan yang lebih tipis akan menghasilkan polymerization shrinkage stress yang lebih kecil. Ketebalan bahan pada penumpatan resin komposit bulk-fill dengan teknik oblique incremental lebih tipis jika dibandingkan teknik bulk dikarenakan penumpatannya yang secara bertahap. Pada ketebalan bahan yang tipis reaksi polimerisasi pada dasar tumpatan lebih teratur dan efisien, sehingga polymerization shrinkage stress akan terdistribusi dengan baik, yang dapat mengurangi tingkat stress pada daerah tepi tumpatan..$^{24,25}$ Ketebalan bahan yang tipis menyebabkan volume resin yang terlibat dalam polimerisasi lebih sedikit. Semakin sedikit volume resin yang terlibat dalam polimerisasi, maka potensi polymerization shrinkage semakin kecil yang menyebabkan stress yang terbentuk juga lebih kecil. ${ }^{21,22}$ Semakin kecil polymerization shrinkage stress yang terbentuk semakin kecil kebocoran mikro yang terjadi.., 24

Kebocoran mikro pada resin komposit bulkfill juga dapat dipengaruhi oleh teknik kondensasi selama penumpatan. ${ }^{26}$ Pada penelitian ini penulis tidak mengendalikan tekanan kondensasi sehingga tekanan yang diberikan pada tiap-tiap sampel berbeda, selain itu polymerization srinkage stress seharusnya dapat diukur besaran nilainya menggunakan alat tensiometer. ${ }^{19}$ Pada penelitian ini penulis tidak menggunakan alat tersebut dan penjelasan mengenai pengaruh polymerization shrinkage stress dalam menyebabkan kebocoran mikro hanya didasarkan pada referensi yang menyatakan bahwa besarnya polymerization shrinkage stress yang terbentuk pada tumpatan dipengaruhi oleh beberapa faktor, yaitu c-factor dan ketebalan bahan.

Teknik penumpatan oblique incremental menghasilkan kebocoran mikro yang lebih kecil dibandingkan teknik penumpatan bulk. Penumpatan resin komposit bulk-fill dengan ketebalan bahan tipis diikuti dengan rendahnya nilai c-factor menyebabkan polymerization shrinkage stress yang terbetuk kecil, hal ini menyebabkan teknik oblique incremental mengahasilkan integritas marginal tumpatan lebih baik dibandingkan teknik penumpatan yang direkomendasikan oleh pabrik resin komposit bulk-fill yaitu secara bulk.

\section{KESIMPULAN}

Resin komposit bulk-fill dengan teknik oblique incremental menghasilkan kebocoran mikro yang lebih kecil dibandingkan teknik bulk.

\section{DAFTAR PUSTAKA}

1. Anusavice, Kenneth J. Buku ajar ilmu bahan kedokteran gigi. Jakarta: EGC. 2003.

2. Singh, Gurkeerat. Textbook of orthodontics $2^{\text {nd }}$ Edition. New Delhi: Jaypee Brother; 2007: 384 $-395$.

3. Xuedong. Dental caries principles and management. China: Springer; 2015: 123 125.

4. Wilson, Nairn HF. Essentials of esthetic dentistry volume one. London: Elsevier; 2015: 193 - 199.

5. John JM. Basic dental materials $2^{\text {nd }}$ edition. New Delhi: Jaypee Brothers. 2003: 143-148.

6. Souza, Fernando DCPPD, Brahim DF, Luciana AC, Lucas DFRG, Simonides C. Polymerization shrinkage stress of composites photoactivated by different light sources. Braz Dent J. 2009. 20(4): 319 - 324.

7. Filtek Bulk Fill Posterior Restorative. Technical product profile. USA: 3M ESPE; 2014.

8. Al SE. Comparison of microleakage between bulk fill flowable and nanofilled resin-based composites [dissertation]. Proquest LLC: Tufts University; 2013.

9. Nadig, Roopa R, Anupriya Bugalia, Usha G, Karthik J, Raghoothama R, Vedhavathi B. Effect of four different placement techniques on marginal microleakage in class II composite 
restorations: an in vitro study. World Journal of Dentistry. 2011. 2(2): 111 - 116.

10. Furness A, Tadros MY, Looney SW, Rueggeberg FA. Effect of bulk/incremental fill on internal gap formation of bulk-fill composites. J Dent. 2014. 42(4): 439 - 449.

11. Moezyzadeh M, Kazemipoor M. Effect of different techniques on microleakage of class $\mathrm{V}$ composite restorations. Journal of Dentistry, Tehran University of Medical Science. 2009; 6(3): $121-129$.

12. Secilmis A, Dilber E, Ozturk N, Yilmaz FG. The effect of storage solution on mineral content of enamel. Material Science and Applications. 2013. 4: $439-445$.

13. Roberson TM, Heymann HO, Swift EJ. Sturdevant's art and science of operative dentistry. 4th ed. Missouri: Mosby; 2002: $190-207,476-8,503-5$.

14. Al-Nori, Ammar KH. The early microleakage of a flowable composite in class $\mathrm{V}$ restorations. Al-Rafidain Dental Journal. 2009. 9(2): 156 161.

15. Gasgoos, Saad S, Ra'ed J Sa'id. The effect of thermocycling on shear bond strength of two types of self etch primers. Al-Rafidain Dent J. 2009. 9(2): $246-253$.

16. Hatrick, Carol D. Dental material clinical applications for dental assinstants and dental hygienists. Edisi III. St. Louis: Elsevier. 2015: $66-71$.

17. El Korashy. Post-gel shrinkage strain and degree of conversion of preheated resin composite cured using different regimens. Operative Dentistry. 2010. 35(2): 172 - 179.

18. Narene AVK, Veniashok $B$, Subbiya A, Vivekanandhan $P$, Sukumaran VG. Polymerization shrinkage in resin compositea review. Middle-East Journal of Scientific Research. 2014. 21(1): 107 - 112.
19. Antonucci, Joseph M, Giuseppetti AA, O'Donnell JNR, Schumacher GE,Skrtic D. Polymerization stress development in dental composites: effect of cavity design factor. Materials. 2009. 2: $169-180$.

20. Choi, S-Mo,Choi GW, Choi KK, Park SJ. Effect of cavity configuration on bond strength and microleakage of composite restoration. Department of Conservative Dentistry. 2002. 27(5): $479-487$.

21. Giachetti, Luca, Russo DS, Bambi C, Grandini R. A review of polymerization shrinkage stress: current techniques for posterior direct resin restorations. The Journal of Contemporary Dental Practice. 2006. 7(4): 1 - 14.

22. Son, Sung-Ae, Roh HM, Bock H, Kwon YH, Park JK. The effect of resin thickness on polymerization characteristic of siloranebased composite resin. Reasearch Article. 2014. 39(4): $310-318$.

23. Flury, Simon, Hayoz S, Peutzfeldt A, Husler J, Lussi A. Depth of cure of resin composites: is the ISO 4049 method suitable for bulk fill materials? Dental Materials. 2012. 28: 521 528.

24. Pfeifer CSC, Braga RR, Cardoso PEC. Influence of cavity dimensions, insertion technique and adhesive system on microleakage of class $\mathrm{V}$ restorations. JADA. 2006. 137: $197-202$.

25. Hernandes, Natalia MAP, Catelan A, Soares GP, Ambrosano GMB, Lima DANL, Marchi GM, Martins LRM, Aguiar FHB. Influence of flowable composites and restorative technique on microleakage of class II restorations. Journal of Investigative and Clinical Dentistry. 2014. 5: 283 - 288.

26. Amar, Ben, Slutzky H, Matalon S. The influence of 2 condensation techniques on the marginal seal of packable resin composite restorations. Abstracts Letters 235. Quintessence Int. 2007. 38(5): $423-428$. 